\title{
Circuito elétrico auxiliar para intubação das vias lacrimais
}

\author{
Auxiliary electrical device for lacrimal system intubation
}

\author{
José Byron Vicente Dias Fernandes ${ }^{(1)}$ \\ Suzana Matayoshi ${ }^{(2)}$ \\ Wilson Komatsu ${ }^{(3)}$ \\ Henrique S. Kikuta ${ }^{(4)}$ \\ Eurípedes da Mota Moura ${ }^{(5)}$
}

\begin{tabular}{|l|}
\hline RESUMO \\
\hline Objetivo: Apresentam num circuito elétrico auxiliar para a intu- \\
bação de vias lacrimais. \\
Método: Descreve-se o dispositivo e sua utilização em 40 pacientes \\
com obstrução congênita ou traumática das vias lacrimais. \\
Resultados: $O$ estudo das características elétricas do aparelho \\
mostrou suas vantagens em relação a outros dispositivos citados na \\
literatura. O uso do aparelho facilitou a recuperação das sondas de \\
Crawford em todos os pacientes. \\
Conclusão: O CAI mostrou-se eficiente e seguro sendo que seu \\
emprego permitiu uma rápida localização e apreensão da sonda de \\
Crawford na cavidade nasal.
\end{tabular}

Palavras-chave: Vias lacrimais; Intubação.

\section{INTRODUÇÃO}

A intubação da via lacrimal com silicone é um procedimento amplamente empregado para o restabelecimento da integridade anatômica e funcional da via lacrimal.

O procedimento, entretanto, é difícil para o oftalmologista, pois requer conhecimento e familiaridade da anatomia nasal ${ }^{1-4}$.

Gavaris idealizou uma lanterna com circuito para testar a acurácia da sondagem ${ }^{5}$. Bargun descreveu a utilização de um ohmímetro para auxiliar a intubação das vias lacrimais ${ }^{6}$.

O objetivo deste trabalho é apresentar um dispositivo elétrico simples, desenvolvido com a finalidade de facilitar a recuperação do silicone no meato inferior, bem como atestar a acurácia de uma sondagem comum.

\section{MATERIAIS E MÉTODOS}

O dispositivo consiste de um circuito elétrico que funciona com uma bateria de lítio de 3 volts em série com uma lâmpada tipo LED (light emitting diode). O conjunto fica alojado em uma caixa plástica de dimensões $4 \mathrm{~cm} \mathrm{x} 3 \mathrm{~cm} \times 1 \mathrm{~cm}$, com uma abertura para a saída de 2 fios finos com comprimento médio de $30 \mathrm{~cm}$ cada um. O fio termina num prendedor (clip) que funciona como um interruptor (Fig.1).

O funcionamento do aparelho na ligação elétrica (acendimento da lâmpada) foi medido com osciloscópio Tektronix 2201 e medidor de corrente Tektronix AM503. Foi feita ainda uma comparação com outro aparelho que utiliza uma lâmpada incandescente ${ }^{6}$.

Este aparelho é utilizado na intubação de vias lacrimais conjuntamente com a 


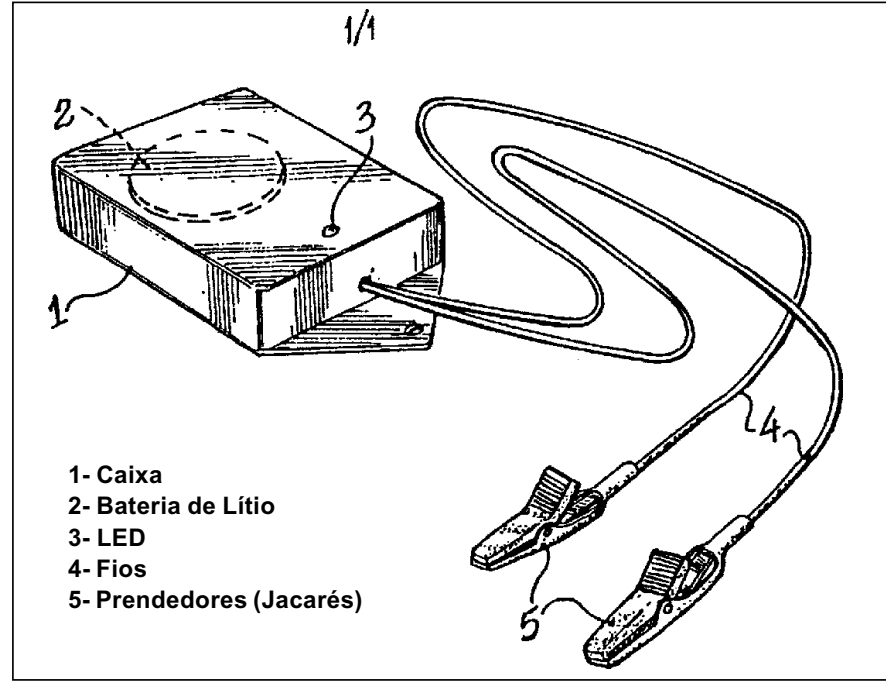

Fig. 1 - Circuito Auxiliar de Intubação (CAI)

sonda e o gancho de Crawford. O procedimento é o mesmo de uma intubação normal, sendo a sonda passada através do ponto lacrimal dilatado, canalículo, saco lacrimal, ducto lácrimo-nasal e meato inferior. Finda essa etapa, um dos prendedores é engatado ao cabo do gancho de Crawford enquanto o outro é preso à extremidade superior da sonda. Quando o gancho de Crawford é introduzido na região lateral e inferior do meato inferior (cerca de $25 \mathrm{a} 35 \mathrm{~mm}$ da narina), ao estabelecer-se o contato metálico sonda-gancho, o circuito elétrico é fechado acendendo-se o LED. O acendimento intermitente do LED indica um contato instável entre a sonda e o gancho. Neste caso, o cirurgião deve tentar levar o gancho ao encontro da sonda de modo a conseguir a manter a iluminação contínua do LED, significando assim que a sonda está bem engatada no gancho. O siliconeé puxado inferiormente e o processo é repetido para a outra extremidade da sonda de Crawford (Fig.2).

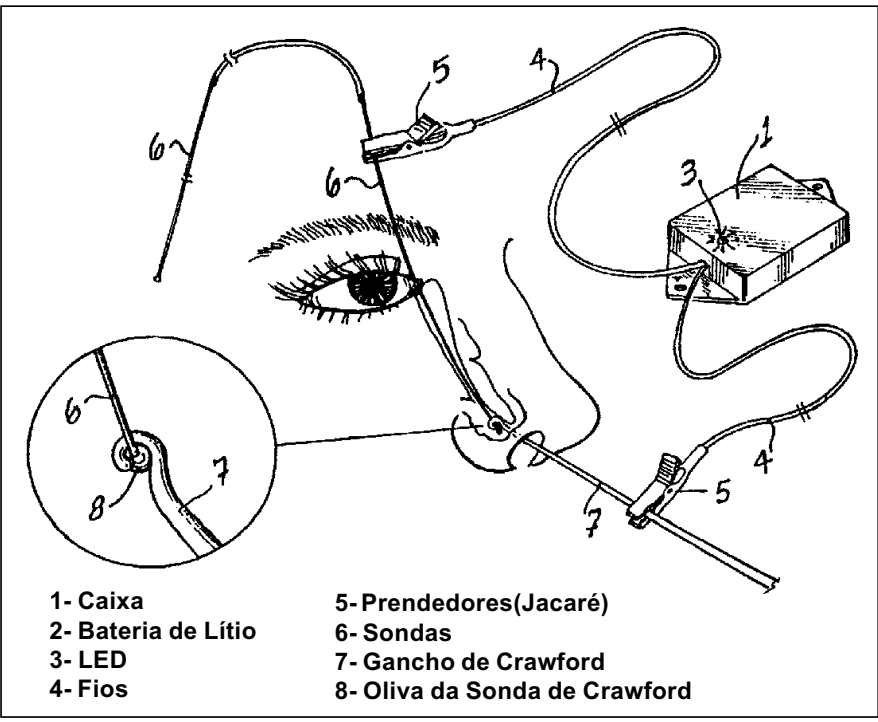

Fig. 2 - Esquema de uso do CAl em uma intubação.
O equipamento foi utilizado nas cirurgias de intubação de vias lacrimais em pacientes:

1) Com diagnóstico de obstrução congênita de vias lacrimais que tiveram insucesso com a sondagem simples;

2) Como primeiro procedimento em casos com obstrução congênita em crianças com idade acima de 15 meses;

3) Na laceração traumática de canalículo lacrimal.

A eficácia do método consiste na comprovada facilidade da localização da sonda de Crawford na fossa nasal.

O desempenho do aparelho na ligação elétrica (acendimento da lâmpada) mostrou que a corrente de ligação do CAI é 60 (sessenta) vezes menor que a do circuito de Gavaris, e, em operação, é 12,5 (doze e meio) vezes menor.

Foram realizadas 40 intubações de VL no período de junho de 1998 a junho de 1999. Vinte e cinco (25) casos eram provenientes do Hospital das Clínicas (HC) e quinze (15) da clínica particular de um dos autores (JBVDF). Todos os pacientes foram submetidos ao procedimento sob anestesia geral. Os 25 procedimentos do HC foram realizados por médicos residentes sob supervisão de um dos autores. Em relação à lateralidade, a maioria dos casos foi unilateral (32 casos).

As sondas de Crawford foram recuperadas na narina em todos os casos com poucas tentativas de "pesca". O piscar do LED indicou em todas as vezes o contato sonda-gancho (Fig.3).

\section{RESULTADOS E DISCUSSÃO}

O passo mais difícil da intubação lacrimal é a recuperação do silicone no meato inferior. Nas crianças o meato é estreito, com pouco espaço entre a parede lateral, o corneto inferior e o assoalho nasal ${ }^{7}$.

Existem várias maneiras de recuperar o silicone do nariz dependendo do sistema de intubação utilizado. Um dos mais difundidos em nosso meio é a sonda de Crawford que utiliza um gancho específico que captura a sonda por um sistema de encaixe da oliva. $\mathrm{O}$ procedimento em geral é realizado às cegas, sendo que o cirurgião se baseia no seu conhecimento da anatomia do meato inferior aliado ao tato e à percepção

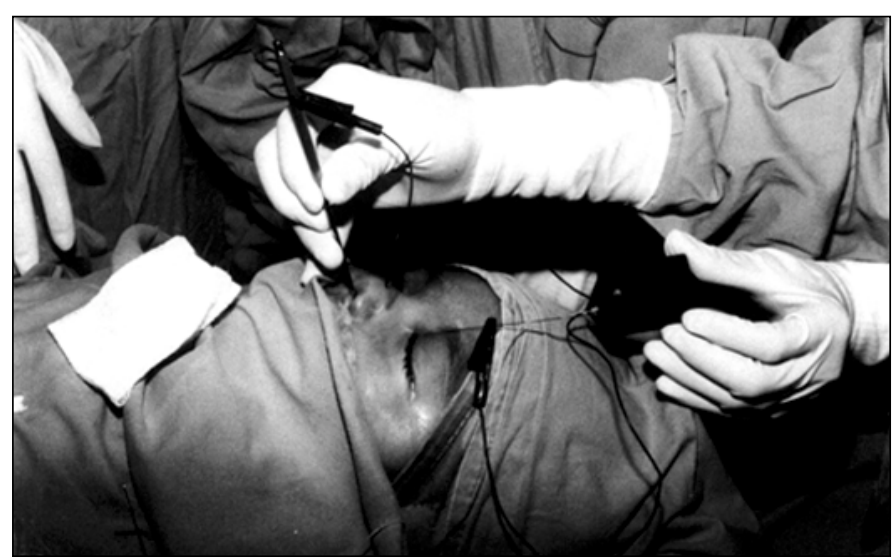

Fig. 3 - CAI em uso. 
auditiva do contato metálico da sonda com o gancho. Torna-se importante, pois, a experiência do cirurgião para que o procedimento seja realizado rapidamente e com sucesso.

Fibroscópios também são empregados para visualizar a extremidade da sonda no meato, mas freqüentemente não são aplicáveis, porquanto são caros, além de não estarem disponíveis em todos os hospitais e muitas vezes não conseguirem penetrar no espaço exíguo sob o corneto inferior.

Quando se fecha um circuito elétrico ocorre um pico de corrente (corrente de ligação. No CAI este pico é de cerca de $25 \mathrm{~mA}$ (que é praticamente igual à própria corrente de funcionamento). No aparelho de Gavaris este pico chega até 1,5 A (corrente de funcionamento de $200 \mathrm{~mA}$ ). No procedimento operatório, as diversas tentativas de apreensão da sonda geram sucessivos picos de corrente, que no caso do aparelho de Gavaris levam ao aquecimento e eventualmente a queimaduras térmicas ${ }^{8}$.

A vida de armazenamento ("shelf-life") da bateria do CAI é tipicamente de 10 (dez) anos, a da bateria do dispositivo de Gavaris é de cerca de 5 (cinco) anos. Além disso, a vida útil da lâmpada do CAI é medida em milhares de horas, ao passo que a do dispositivo de Gavaris o é em centenas de horas, ou seja, é uma alternativa mais econômica.

O dispositivo de Bargun é constituído por um medidor eletromecânico delicado que utiliza o mesmo tipo de bateria de Gavaris. Obriga ainda o cirurgião a manter contato visual constante na escala do aparelho. O CAI, em contraste, necessita somente do uso da visão periférica do cirurgião, que assim pode concentrar-se no campo operatório. O dispositivo CAI tem operação mais simplificada por não exigir ajuste de escala como o dispositivo de Bargun.

Em resumo, o CAI é mais prático e mais seguro para o uso cirúrgico, tem baixo consumo energético; a bateria de lítio apresenta menor intensidade de corrente quando comparada com pilhas normais.

$\mathrm{O}$ aparelho permite que o cirurgião não apenas sinta $o$ contato metal-metal mas faz com que saiba que o que está sendo manipulado com o gancho é o metal da sonda e não outras estruturas sólidas como cornetos ou partes ósseas. A eficácia do sistema foi comprovada nos casos clínicos em que sua utilização permitiu uma rápida localização e recuperação da sonda, mesmo quando realizada por médicos em treinamento não familiarizados com as vias lacrimais.

\section{SUMMARY}

Purpose: To present an auxiliary electrical circuit (CAI) for lacrimal system intubation.

Method: The device is described as well as its application to 40 patients with congenital and traumatic lacrimal obstruction.

Results: An electrical characteristics study of CAI was performed and compared to other instruments reported in the literature, showing its advantages. Its use helped the retrieval of Crawford probes in all patients.

Conclusions: CAI is safe and effective. Its use allows a quick localization and retrieval of Crawford probe even when performed by trainee physicians not familiar with lacrimal anatomy.

Keywords: Lacrimal system; Intubation.

\section{REFERÊNCIAS BIBLIOGRÁFICAS}

1. Bison S, Soccol O. Confecção artesanal de arame de Johnson. Arq Bras Oftal 1988;61(5);599-601.

2. Dibble RF, Friedel SD. A Simplified method of monocanalicular silicone intubation. Ophthalmic Surg 1990;21:134-5.

3. França VP, Rayes A, Deboni JA, Moura EM. Obstrução lacrimal do recémnascido. In: Soares EJC, Moura EM Gonçalves JO, eds. Cirurgia Plástica Ocular. São Paulo: Roca, 1997,479-92.

4. Kikuta HS. Lacerações canaliculares. In: Moreira Jr., CA, Kikuta HS, Freitas D, eds. Trauma Ocular. Rio de Janeiro: Cultura Médica, 1997, capítulo 19.

5. Gavaris PT. Lacrimal duct probing light. Trans Am Acad Ophtalmol Otolaringol 1976;18:118-9.

6. Bargum R. Ohmmeter-guided nasolacrimal intubation. Opthalmic Surg 1992;23:827-8.

7. Katowitz JA, Hollsten DA. Silicone intubation of the naso lacrimal drainage system. In: Linberg JV, ed. Lacrimal Surgery. New York: Churchill Livingstone, 1988, capítulo 6.

8. Commission Électrotechnique Internacionale. Effets du courant passant par le corps humain (Publication 479-1). Genève. 1984.

\title{
Novidades na Internet!!!
}

\author{
Agora no site CBO você tem disponível todas as informações na íntegra dos \\ Arquivos Brasileiros de Oftalmologia \\ http://www.cbo.com.br/abo
}

